\title{
BIRDS AS PREDATORS IN TROPICAL AGROFORESTRY SYSTEMS
}

\author{
Sunshine A. Van Bael, ${ }^{1,6}$ Stacy M. Philpott, ${ }^{2,7}$ Russell Greenberg, ${ }^{2}$ Peter Bichier, ${ }^{2}$ Nicholas A. Barber, ${ }^{3}$ \\ Kailen A. Mooney, ${ }^{4}$ and Daniel S. Gruner ${ }^{5,8}$ \\ ${ }^{1}$ Smithsonian Tropical Research Institute, Unit 0948, APO, AA 34002 USA \\ ${ }^{2}$ Smithsonian Migratory Bird Center, National Zoological Park, Washington, D.C. 20008 USA \\ ${ }^{3}$ Department of Biology, University of Missouri, One University Boulevard, St. Louis, Missouri 63121 USA \\ ${ }^{4}$ Department of Ecology and Evolutionary Biology, University of California, Irvine, California 92697-2525 USA \\ ${ }^{5}$ Bodega Marine Lab, University of California-Davis, P.O. Box 247, 2099 Westside Road, Bodega Bay, California $94923-0247$ USA
}

Abstract. Insectivorous birds reduce arthropod abundances and their damage to plants in some, but not all, studies where predation by birds has been assessed. The variation in bird effects may be due to characteristics such as plant productivity or quality, habitat complexity, and/or species diversity of predator and prey assemblages. Since agroforestry systems vary in such characteristics, these systems provide a good starting point for understanding when and where we can expect predation by birds to be important. We analyze data from bird exclosure studies in forests and agroforestry systems to ask whether birds consistently reduce their arthropod prey base and whether bird predation differs between forests and agroforestry systems. Further, we focus on agroforestry systems to ask whether the magnitude of bird predation (1) differs between canopy trees and understory plants, (2) differs when migratory birds are present or absent, and (3) correlates with bird abundance and diversity. We found that, across all studies, birds reduce all arthropods, herbivores, carnivores, and plant damage. We observed no difference in the magnitude of bird effects between agroforestry systems and forests despite simplified habitat structure and plant diversity in agroforests. Within agroforestry systems, bird reduction of arthropods was greater in the canopy than the crop layer. Top-down effects of bird predation were especially strong during censuses when migratory birds were present in agroforestry systems. Importantly, the diversity of the predator assemblage correlated with the magnitude of predator effects; where the diversity of birds, especially migratory birds, was greater, birds reduced arthropod densities to a greater extent. We outline potential mechanisms for relationships between bird predator, insect prey, and habitat characteristics, and we suggest future studies using tropical agroforests as a model system to further test these areas of ecological theory.

Key words: agroforestry systems; birds; insectivory; meta-analysis; top-down; trophic interactions; tropical ecosystems.

\section{INTRODUCTION}

Increasingly, ecologists are focusing on the role of predators in reducing the abundance of their prey base and the implications for plants that directly or indirectly provide resources for the prey species (Schmitz et al. 2000). Considerable variation in the strength of topdown control has stimulated research into mitigating factors, such as variation in nutrient resource availability, habitat complexity, or qualitative condition of plants (Cebrian and Lartigue 2004), the diversity and composition of predator assemblages (Sih et al. 1998, Schmitz 2007), and temporal or seasonal variation in

Manuscript received 28 November 2006; accepted 12 February 2007; final version received 2 April 2007. Corresponding Editor (ad hoc): I. Perfecto. For reprints of this Special Feature, see footnote 1, p. 913.

${ }^{6}$ E-mail: vanbaels@ si.edu

${ }^{7}$ Present address: Department of Environmental Sciences, University of Toledo, Toledo, Ohio 43606 USA.

${ }^{8}$ Present address: Department of Entomology, University of Maryland, College Park, Maryland 20742 USA. these factors (Gratton and Denno 2003, Mooney and Linhart 2006). Insectivorous birds are ubiquitous across a broad range of terrestrial ecosystems, and a growing number of experimental field manipulations of insectivorous bird activity (primarily via exclosures of netting) have shown measurable and often strong reductions in the standing crop of arthropods, including important groups of herbivores (Mols and Visser 2002). A smaller number of studies have shown that the reduction in herbivores further decreases herbivore damage and, sometimes, the overall growth rate or standing biomass of plants (e.g., Marquis and Whelan 1996, Van Bael and Brawn 2005). Considering the wide variation in effects documented across experimental studies, a quantitative synthesis is needed to understand patterns and mechanisms of top-down control across natural and managed forested systems.

Studies throughout Latin America have documented high abundance and diversity of insectivorous birds in shaded coffee and cacao agroforestry systems (Perfecto et al. 1996, Rice and Greenberg 2000). Although agroforestry systems share some qualities with native 
TABLE 1. Review of effect sizes from bird exclosure studies in agroforestry systems of Central America.

\begin{tabular}{|c|c|c|c|c|c|c|}
\hline \multirow{2}{*}{$\begin{array}{c}\text { Focal plant } \\
\text { and location }\end{array}$} & \multirow[b]{2}{*}{ Habitat description } & \multirow{2}{*}{$\begin{array}{l}\text { Duration } \\
\text { (months) }\end{array}$} & \multirow[b]{2}{*}{ Insecticides } & \multicolumn{3}{|c|}{ Effect sizes $\dagger$} \\
\hline & & & & All arthropods & Large arthropods & Plant damage \\
\hline \multicolumn{7}{|l|}{ Coffee crops } \\
\hline \multirow{2}{*}{ Guatemala: } & shaded monoculture & 2 & yes & -0.13 & -1.05 & -0.17 \\
\hline & unshaded monoculture & 2 & yes & -1.93 & -1.75 & -0.25 \\
\hline \multirow[t]{4}{*}{ Mexico§ } & traditional polyculture & 24 & no & -0.14 & 0.15 & 0.17 \\
\hline & commercial polyculture 1 & 24 & no & 0.06 & 0.33 & -0.63 \\
\hline & commercial polyculture 2 & 24 & no & -0.10 & -0.17 & -0.18 \\
\hline & shaded monoculture & 24 & no & 0.21 & -0.29 & -0.34 \\
\hline Puerto Rico & commercial polyculture & 4 & - & -0.16 & -1.32 & NA \\
\hline \multicolumn{7}{|l|}{ Cacao crops } \\
\hline Panama\# & traditional polyculture & 12 & no & -0.11 & -0.64 & -0.37 \\
\hline \multicolumn{7}{|l|}{ Inga spp. } \\
\hline Guatemala\| & shade trees over coffee & 2 & no & -0.55 & -1.09 & -0.08 \\
\hline \multirow{2}{*}{ Mexicot† } & shade trees over coffee 1 & 2 & no & -0.47 & -1.54 & NA \\
\hline & shade trees over coffee 2 & 2 & no & -0.89 & -1.07 & NA \\
\hline \multicolumn{7}{|l|}{ Various species } \\
\hline Mexicott & tree patch in pasture & 2 & no & -1.36 & NA & NA \\
\hline
\end{tabular}

$\dagger$ Effect sizes are calculated as $\ln ($ response ratios), i.e., $\ln ($ control mean/exclosure mean). More negative effect sizes indicate a stronger effect of birds.

\$ Data from Greenberg et al. (2000). Unshaded monoculture coffee from this study was excluded from the agroforest vs. forest analysis, as it was not grown in an agroforest.

§ I. Perfecto, R. Greenberg, G. Ibarra-Nuñez, P. Bichier, C. E. Gordon, A. Garcia-Ballinas, and G. Lopez Bautista (unpublished manuscript). This study examined bird effects in four farms, under three different shade management regimes. At time of exclosure establishment, site 1 had slightly higher density and diversity of shade trees, and site 2 had relatively less density and diversity of shade trees. During the two years exclosures were maintained, management on the two farms became more similar.

- Borkhataria et al. (2006).

\# Van Bael et al. (2007).

|| Greenberg et al. (unpublished data), same site and authors as Greenberg et al. (2000).

$\dagger \dagger$ Philpott et al. (2004); treated as two separate studies because different exclosures were used on different trees in the dry (1) and wet (2) seasons.

\$t Greenberg and Ortiz (1994).

forest, agroforest habitats ordinarily are both structurally and floristically simpler than forests and are relatively homogeneous in species composition and structure compared with tropical forests. The intermediate complexity of agroforestry systems hence provides a potential model system for understanding ecological aspects of top-down control in terrestrial systems. Recent studies have used exclosure experiments in shaded agroforests to quantify the effects of bird insectivory on arthropod densities and plant damage (Table 1). Many of these studies are notable in that bird abundance and diversity were documented quantitatively: a rarity in the literature from natural forests. This replication of exclosure studies across a range of locations and management regimes in tropical agroforestry systems allows for a comparative analysis among agroforestry studies and between agroforestry and tropical forest studies. Although the impetus for exclosure studies in shaded agroforestry systems has often been to evaluate the potential of bird predation for biological control, we use this range of vegetative complexity and structure among natural forests and agroforests to address basic ecological questions. We present a meta-analysis of data from exclosure studies to assess and compare the overall effect size of insectivorous birds in forests and agroforestry systems. Within forests, we compare bird effects in tropical and temperate systems in order place our tropical results in a larger ecological context. We then focus on agroforestry systems to ask whether the magnitude of bird predation (1) differs between canopy trees and understory plants, (2) differs when migratory birds are present or absent, and (3) correlates with bird abundance and diversity. We discuss how this research from agroforestry systems approaches broader ecological theory and suggests future studies.

\section{Methods \\ Literature search, effect size calculations, and meta-analysis}

We compiled a database of published and unpublished studies that fulfilled all three of the following criteria: (1) netted exclosure experiments were constructed and paired with appropriate open controls, (2) trees were the dominant upper strata vegetation (forested landscapes rather than shrublands or grasslands), and (3) exclosures were placed in the shrub and/or canopy layer (not the understory herb/seedling layer) (Appendix A). In all studies, birds were the focal vertebrate of interest, but some experiments necessarily excluded leafgleaning bats and lizards concomitantly with birds. The final data set consisted of 48 studies, with 11 and 37 studies in agroforests and forests, respectively. All 
TABLE 2. Comparison of effect sizes (response ratios) from bird exclosure studies in agroforests and forests.

\begin{tabular}{|c|c|c|c|c|c|c|c|c|c|}
\hline \multirow[b]{2}{*}{ Variable } & \multicolumn{2}{|r|}{ Agroforest } & \multicolumn{2}{|r|}{ Forest } & \multicolumn{3}{|c|}{ Comparison } & \multicolumn{2}{|r|}{ Overall } \\
\hline & $n$ & Mean effect size (CL) & $n$ & Mean effect size (CL) & $Q$ & $\mathrm{df}$ & $P$ & $n$ & Mean effect size (CL) \\
\hline & 1 & & & & & & & & \\
\hline ods & 11 & -0 & 30 & -0 . & 1. & 1 , & 0. & 4 & $-0.61(-$ \\
\hline Herbivores & 11 & $-0.60(-0.89,-0.36)$ & 29 & $-0.60(-1.0,-0.22)$ & 0.001 & 1,38 & 0.99 & 40 & $-0.60(-0.90,-0.30)$ \\
\hline Carnivores & 11 & $-0.53(-0.81,-0.29)$ & 23 & $-0.79(-1.09,-0.48)$ & 0.497 & 1,32 & 0.31 & 34 & $-0.71(-0.95,-0.49)$ \\
\hline
\end{tabular}

Notes: Effect sizes were calculated as $\ln$ (response ratios), i.e., $\ln ($ control mean/exclosure mean). Bootstrap confidence intervals, representing a $95 \%$ confidence limit, are used throughout this table; $n$ is the number of studies in the calculation of mean effect size. The $Q$ statistic partitions the total heterogeneity into variance explained by the model and the residual error not explained by the model ( $Q$ is similar to $F$ in an ANOVA test). See Methods for resampling details.

agroforest studies and six of the forest studies were in tropical systems. For agroforestry studies, we classified the level of management intensity of each site using author descriptions of the shade tree canopy (i.e., percent cover, tree diversity, tree density) to assign systems to the categories of Moguel and Toledo (1999). The studies are listed in the online supporting information (Appendix B).

For comparisons among the tropical agroforestry studies, which employed similar methodologies, we describe effects using intuitively simple percent reduction in arthropod numbers due to bird predation. To compare agroforestry studies with the larger and more methodologically heterogeneous set of forest studies, we calculated effect sizes for each study using log response ratios ( $\ln R$ ) where $\ln R=\ln ($ control mean) $\ln$ (exclosure mean) (this is equivalent to $-[\ln ($ treatment mean/control mean)] [Hedges et al. 1999]). Where possible, we calculated effect sizes for bird predation on all arthropods, large arthropods $(>5 \mathrm{~mm})$, herbivorous arthropods and carnivorous arthropods, and the percentage of leaf area damaged by herbivores. For all variables, more negative effect sizes indicate a larger reduction due to bird predation and zero corresponds to no effect. We used endpoint values to calculate effect sizes when studies reported repeated measures (Appen$\operatorname{dix}$ A).

Differences in mean effect size between agroforests and forests (and between temperate and tropical forests) were calculated using a fixed-effects model (categorical summary analysis with the $Q$ statistic; Metawin 2.0, Sinauer Associates, Sunderland, Massachusetts, USA). The $Q$ statistic partitions the total heterogeneity into variance explained by the model and the residual error not explained by the model ( $Q$ is similar to $F$ in an ANOVA test). To compare effect sizes within and between systems, we treated all studies as equal replicates and did not weight the individual effect sizes by their variance. Besides the fact that variance estimates were unavailable for some studies, weighting increases the influence of small-scale but well replicated studies relative to large-scale but potentially more realistic studies. Excluding variance does not bias the overall effect sizes, but may result in reduced statistical power (i.e., real differences between systems are less detectable but tests are more conservative with respect to type I error [Hedges et al. 1999]). We calculated bootstrap confidence intervals around mean effect size estimates for agroforest, forest, and overall effect sizes (Metawin 2.0). The data were resampled 999 times with replacement to generate a distribution, from which the highest and lowest $2.5 \%$ values were used to represent upper and lower $95 \%$ confidence limits.

\section{Bird census data and predatory effects}

With bird point count data provided by authors of the tropical agroforest exclosure studies $(n=9$ sites), we tested for relationships between predation effects and bird richness (number of species per number of rarefied individuals) and abundance. Bird sampling in each study site consisted of between 38 and 41025 m radius, 10minute point counts, the majority of which were conducted by the same two observers (P. Bichier and R. S. Greenberg), thereby lessening observer bias among studies. We limited the bird data sets for analysis to only insectivores (including omnivores) found in the strata in which exclosures were placed. We further limited point count (and percentage reduction in arthropods) data to the dry season, when (1) migrants were present and (2) resident birds were not breeding. We compared these point count data to predatory effect data also limited to only the dry season. Changes in the behaviors and activities of resident birds in the breeding season may significantly alter their effects on arthropods (Greenberg 1995). The proportions of migrant and resident individuals at the study sites were $66 \% \pm 5 \%$ and $34 \% \pm 5 \%$ (mean $\pm \mathrm{SE}$ ), respectively. We examined the data for correlations between six bird variables (the richness and abundance of all insectivorous birds, migrants, and residents) and the percentage reduction in total and large (>5 mm) arthropods (Appendix A).

\section{RESUlts AND Discussion}

\section{Overall effects of bird predation and habitat comparison}

The overall mean effect sizes from bird exclosure experiments suggest that birds consistently reduce arthropods and plant damage in forests and agroforestry systems (Table 2). Three recent meta-analyses reported comparable effect sizes for predation on herbivores in terrestrial systems (Schmitz et al. 2000, Halaj and Wise 

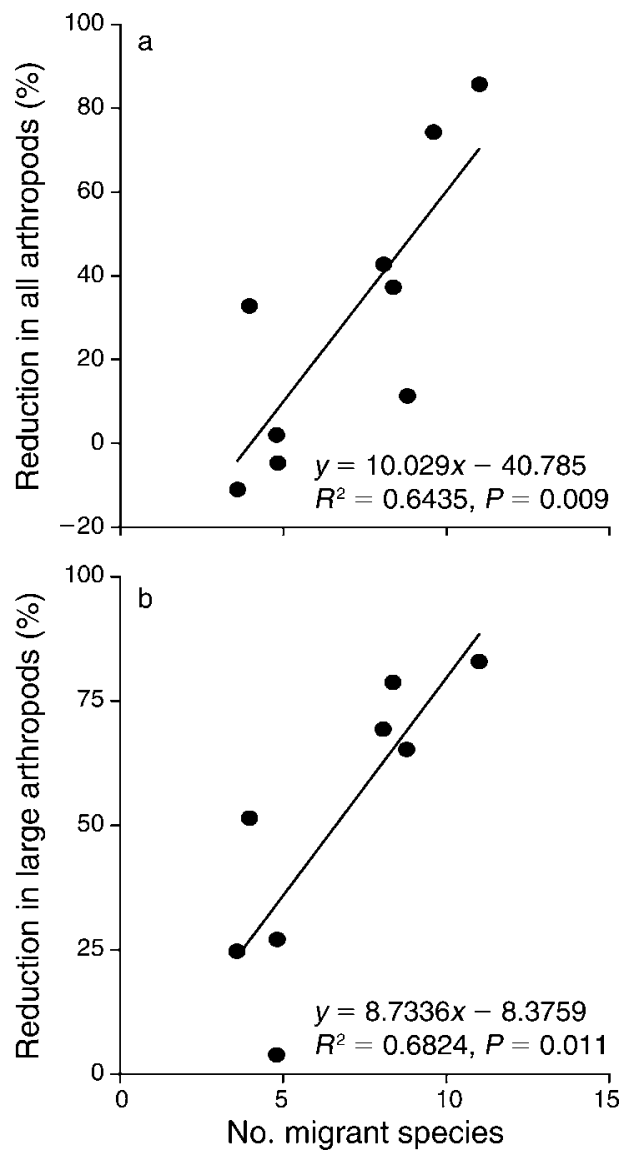

FIG. 1. Bird effects on (a) all and (b) large $(>5 \mathrm{~mm})$ arthropods as a factor of migrant bird diversity. Each point represents bird data for only omnivorous and insectivorous birds that primarily forage in the strata in which bird exclosures were placed. Species numbers were rarefied to the maximum number of individuals observed in the site with the lowest bird abundance (see Appendix A for details). Correlations were determined using linear regressions with the percentage reduction of all or large arthropods as the dependent variable and species diversity as the independent variable. Panel (b) contains one less data point because one study did not separate large arthropods.

2001, Shurin et al. 2002). All analyses were dominated by studies where the predators were invertebrates, and two included agricultural systems (Schmitz et al. 2000, Halaj and Wise 2001). Halaj and Wise (2001) used Hedges $d$ as their effect size statistic, and their results could not be compared directly. However, our measurement of herbivore response to bird predation (overall herbivore $\log$ ratio $=-0.60,95 \% \mathrm{CL}-0.90$ to -0.30 , Table 2) is similar to invertebrate predator removal natural $\log$ response ratios previously reported (herbivore $\log$ ratio $=-0.49, \mathrm{CL}-0.63$ to -0.35 , sign reversed for comparison [Schmitz et al. 2000]; herbivore log ratio $=-0.45, \mathrm{CL}-0.70$ to -0.20 , from Shurin et al. [2002]: Fig. 1).

In terrestrial food webs, the impact of predators on herbivores tends to be large relative to their effects on vegetation (Schmitz et al. 2000, Halaj and Wise 2001, Shurin et al. 2002). Accordingly, birds had a greater impact on arthropods than on plant damage in agroforestry and forest systems (Tables 1 and 2). In most studies where plant damage was measured, the effect sizes show some damage reduction where birds foraged, but the effect size magnitudes are small (Table 2). Our overall effect size for predation on plant damage (plant damage $\log$ ratio $=-0.32, \mathrm{CL}-0.45$ to -0.20 , Table 2) was much lower than that reported by Schmitz et al. (2000) (plant damage log ratio $=-0.95, \mathrm{CL}-1.18$ to -0.72). These analyses have only two studies in common, suggesting that invertebrate predators (which comprise the majority in Schmitz et al. 2000) may have larger relative effects on plant damage than they do directly on herbivores. However, because the effects of plant damage accumulate through time, and compensatory growth may occur within individual shrubs and trees, the impacts of bird predation on tree or shrub damage as measured by leaf area are difficult to compare across systems unless plant biomass is also reported (Schmitz et al. 2000).

Based on theoretical predictions, we would expect stronger impacts of bird predation in agroforestry systems than in tropical forests. Generally speaking, agroforests are simplified versions of tropical forests, being both structurally less complex and containing reduced biodiversity at all trophic levels. Theory suggests that strong top-down effects of predation will be more likely where complexity and diversity are lower (Polis and Strong 1996, Hulot et al. 2000). In contrast, we found no significant differences between agroforests and forests in the extent to which bird predation affected arthropods or plant damage (Table 2). This was true when we compared the agroforest studies to all forest (Table 2) and to tropical forest studies $(P>0.05$ for all arthropods and plant damage). No studies were available for temperate agroforestry systems, and the sample sizes for tropical forests were relatively small compared to temperate forests. Thus, we increased the power of these comparisons by aggregating temperate and tropical forest studies in Table 2. This was justified because effect sizes were similar in the two forest types (mean [CL] effect size on plant damage, -0.36 [ -0.57 to $-0.15]$ and -0.33 [ -0.60 to -0.06$]$, respectively). These low sample sizes highlight gaps in the ecological literature regarding the effects of bird predation in tropical forest systems.

\section{Bird effects in the canopy vs. understory layers of agroforestry systems}

Previous observations in shaded coffee farms suggest that arthropod and bird abundances are greater in the canopy rather than the crop layer (Wunderle and Latta 1996, Greenberg et al. 1997, Jedlicka et al. 2006). We compared bird predation in the canopy and crop layers for three agroforestry studies (Table 1) in Mexico (Philpott et al. 2004, Perfecto et al. 2007) and in 
Guatemala (Greenberg et al. 2000). Birds reduced arthropod abundance by $46.1 \% \pm 11.4 \%$ and $4.5 \% \pm$ $6.4 \%$ in canopy and coffee layers, respectively (paired $t$ test, $\left.t_{2}=4.7, P=0.02\right)$. The trend was marginally significant for large $(>5 \mathrm{~mm})$ arthropods $(70.7 \% \pm 7.0 \%$ vs. $24.3 \% \pm 36.7 \%$ [mean $\pm \mathrm{SD}$ ], paired $t$ test, $t_{2}=2.10$, $P=0.08)$. Similarly, recent studies in tropical forests have demonstrated that bird predation effects on conspecific trees are greater in the canopy than understory (Van Bael and Brawn 2005) and are greater on reproductive trees than saplings (Boege and Marquis 2006). Thus, the small number of studies in agroforestry systems and forests show a consistent pattern of greater bird effects in the canopy.

Canopy and understory/crop layers differ in plant qualities (e.g., productivity, structural complexity, suitability of foliage for herbivores) and environmental qualities (e.g., light, moisture). We suggest that birds may be focusing their foraging in the canopy because greater levels of plant productivity and/or quality result in greater arthropod abundances (e.g., Oksanen et al. 1981). For example, in agroforestry systems, the canopy layer generally consists of one or a few pioneer species selected for their high growth rates and productivity (Pennington 1997), while coffee and cacao cultivars are derived from forest understory saplings or shrubs that have slower growth rates, relatively low photosynthetic output, and tough, long-lived foliage (Matta et al. 2001). These contrasting life-histories lead to the expectation of greater arthropod abundances in the canopy than the crop layer. Agroforestry systems would be ideal settings for future exclosure experiments using fertilization to manipulate plant productivity and quality in order to further explore why bird effects are greater in the canopy.

\section{Seasonality in the magnitude of bird predation effects}

Insectivorous bird populations in the Neotropics may double with the influx of migrants from the North at a time of year when arthropod abundance is thought to be low (September-April; late rainy and dry seasons). Both the diversity and abundance of insectivorous migrants is particularly high in agroforestry systems, making them ideal locations for assessing food limitation for migratory birds in tropical systems. If food resources are limiting in tropical breeding communities, then from where does the surplus arise to support this influx of migrants? The breeding currency hypothesis holds that breeding birds are limited by the abundance of specific food types (large herbivorous insects such as Lepidoptera and Orthoptera, usually $1 \mathrm{~cm}$ or greater in length) required for successful breeding (Greenberg 1995, Johnson et al. 2005). During the nonbreeding season, birds are limited by total arthropod abundance. The food resources available to migrants are set by the difference between these two limits, such that habitats with few large herbivorous insects, but high abundance of total arthropods should support a greater influx of migratory birds. During the "winter" months we expect that the relatively high density of birds and low abundance of arthropods will result in large proportional reductions in arthropod abundance. During the "summer" we would expect a reduced proportional reduction of arthropods, because birds are less common and arthropods are more abundant.

Exclosure studies in agroforestry systems support the proposition that the standing crop of arthropods $>5$ $\mathrm{mm}$ in length is reduced more when migrants are present than when they are absent. We interpret the larger and significant effect in the larger size class of arthropods as reflecting the fact that birds may not prefer very small arthropods: those that constitute the largest share of total arthropods (Gruner 2004). The restriction to $5 \mathrm{~mm}$ and above focuses the analyses on the range of prey commonly taken by birds, but should not be confused with an analysis of the very largest prey used for breeding. For six studies, we had data from both seasons, allowing direct pair-wise comparisons. The reduction (mean $\pm \mathrm{SD}$ ) of large $(>5 \mathrm{~mm}$ ) arthropods by birds was significantly greater when migrants were present relative to when they were absent $(35.8 \% \pm$ $25.9 \%$ vs. $\left.23.8 \% \pm 25.3 \%, t_{5}=3.39, P=0.01\right)$. However, no significant difference was found for percent reduction of total arthropods with $12.0 \% \pm 24.1 \%$ for the season with migrants and $10.8 \% \pm 19.9 \%$ for the season without migrants $\left(t_{5}=0.16, P=0.44\right)$. If the degree to which standing crop of arthropods is reduced is a good indicator of the potential for food limitation, then the prediction from the breeding currency hypothesis that the winter is a season of greater potential food limitation is supported by these comparisons.

\section{Relationships between bird effects, richness, and abundance}

A comparison of two coffee agroforests showed that the effects of birds on experimentally introduced herbivores were greater in a farm with higher bird density and diversity than in a neighboring farm with fewer birds (Perfecto et al. 2004). Comparing predation only in two farms, however, provides limited evidence for the importance of predator diversity in predatory function. Across our gradient of nine sites, we found that species richness of migratory birds showed the strongest correlation with percent reduction of all arthropods and large arthropods (Fig. 1). Correlations were weaker for species richness of all birds (vs. percent reduction in all arthropods, $R^{2}=0.55, P=0.02$; vs. percentage reduction in large arthropods, $R^{2}=0.44, P=$ 0.07 ), and correlations between resident bird richness and arthropod reductions were not significant $(P>$ 0.05). Species density (species per sample) of all, migrant, or resident bird species did not correlate with total or large arthropod reductions $(P>0.05)$; nor did bird density (individuals per sample) of all, migrant, or resident bird species. 
These results provide striking evidence of a relationship between bird effects on arthropods and migrant bird richness, but the mechanisms underlying this relationship deserve further study. The diversity of predator assemblages may influence the top-down effects of predators on lower trophic levels, but the direction and intensity of these effects are matters of active debate in the literature (Sih et al. 1998, Schmitz 2007). For example, predation by a suite of predator species at natural densities decreased herbivore populations and increased plant yields more than a single species of predator alone (Cardinale et al. 2003). Other examples demonstrated that predator diversity can reduce top-down control because of increased intraguild predation and interference (e.g., Finke and Denno 2004). Most experimental studies of predator diversity involve a very small number of arthropod species in small-scale additive or replacement series designs (Schmitz 2007). Our study makes an important contribution to this literature in at least three ways. First, we investigate a suite of vertebrate predators where past work has focused exclusively on arthropods. Second, our data includes a greater range in predator diversity than past studies (from 3 to 11 species). Finally, where arthropod predators commonly consume each other, birds do not, thus simplifying trophic dynamics and providing a clearer view of the effects of predator diversity per se.

Agroforestry systems provide a natural gradient in which to examine the relative impact of predatory guilds with varying diversity and abundance. The downside of this natural manipulation, however, is that the diversity of insectivores at the sites may also co-vary with habitat complexity. Without examining comparable vegetation data from each site, we cannot rule out the possibility that habitat complexity is driving the tight relationship between migrant bird diversity and arthropod suppression.

There are several possible explanations for this positive relationship between bird richness and reduction of arthropod abundance. First, a more diverse suite of predator species may consume more kinds of prey species, either by foraging in more microhabitats or by consuming more individuals or species. Alternatively, in more diverse bird assemblages, the chance is greater that very efficient insectivores will be present (Perfecto et al. 2004). An additional possibility is that predation effects are larger where baseline arthropod abundances are greater, and a greater diversity of birds is attracted to a larger resource base. We found no evidence for this alternative possibility: relationships between bird richness and density (for all birds, migrants, and residents) and baseline arthropod abundance at the sites were nonsignificant ( $P>0.05$ for all correlations).

Our analysis stimulates additional questions to be approached with more data. For example, why does migrant but not resident bird species richness correlate with arthropod reductions? Furthermore, why does the number of species, but not density, correlate to arthropod reductions? Future analyses that incorporate differences in the proportion of insectivores and omnivores in migrant vs. resident assemblages, or differences in sizes and energy requirements of birds may influence or change the observed relationships. Carefully replicated studies in agroforestry systems could potentially isolate the effects of diversity and habitat complexity to examine these hypotheses.

\section{Conclusions and recommendations}

Agroforestry systems present gradients of habitat complexity and species diversity, and provide the ability to conduct large-scale experiments that manipulate predator effects and nutrient input. We highlight areas where recent work in coffee and cacao systems can be applied to basic ecological questions about the importance of vegetation strata, habitat complexity, seasonality, and predator diversity for the strength of multitrophic interactions. Coffee and cacao systems could also be exploited to address additional questions concerning plant quality, productivity and multi-trophic interactions. To our knowledge, no experiments have examined the effects of factorial combinations of nutrients and predation in these systems. Moreover, coffee and cacao systems provide opportunities to study the diversity of prey assemblages on native and introduced crops, as both crops are grown in the old and new world. It has been hypothesized that exotic plants may initially have lower specialist but greater generalist herbivore species after introduction, but that exotics eventually accumulate more specialist species (Strong et al. 1984, Andow and Imura 1994). Finally, our comparison between tropical agroforests and forests highlights a gap in the ecological literature: future studies can be strengthened by replication of exclosure experiments in complex, tropical systems.

\section{AcKNOWLEDGments}

The authors thank E. Herre, E. G. Leigh, Jr., and two anonymous reviewers for comments on the manuscript, and I. Perfecto for sharing unpublished data. This work was supported by NSF IRFP Grant \# OISE-0401957 to S. A. Van Bael, NSF Grant \#DEB-9981526 to I. Perfecto, R. S. Greenberg, and G. Ibarra-Nuñez, and EPA STAR \#FP91648501 to N. A. Barber. K. A. Mooney received support from the University of California-Irvine School of Biological Sciences. This is contribution number 2376, Bodega Marine Lab, University of California-Davis.

\section{Literature Cited}

Andow, D. A., and O. Imura. 1994. Specialization of phytophagous arthropod communities on introduced plants. Ecology 75:296-300.

Boege, K., and R. J. Marquis. 2006. Plant quality and predation risk mediated by plant ontogeny: consequences for herbivores and plants. Oikos 115:559-572.

Borkhataria, R. R., J. A. Collazo, and M. J. Groom. 2006. Additive effects of vertebrate predators on insects in a Puerto Rican coffee plantation. Ecological Applications 16:696-703. Cardinale, B. J., C. T. Harvey, K. Gross, and A. R. Ives. 2003. Biodiversity and biocontrol: emergent impacts of a multi- 
enemy assemblage on pest suppression and crop yield in an agroecosystem. Ecology Letters 6:857-865.

Cebrian, J., and J. Lartigue. 2004. Patterns of herbivory and decomposition in aquatic and terrestrial ecosystems. Ecological Monographs 74:237-259.

Finke, D. L., and R. F. Denno. 2004. Predator diversity dampens trophic cascades. Nature 429:407-410.

Gratton, C., and R. F. Denno. 2003. Seasonal shift from bottom-up to top-down impact in phytophagous insect populations. Oecologia 134:487-495.

Greenberg, R. 1995. Insectivorous migratory birds in tropical ecosystems: the breeding currency hypothesis. Journal of Avian Biology 26:260-263.

Greenberg, R., P. Bichier, A. C. Angón, C. MacVean, R. Perez, and E. Cano. 2000. The impact of avian insectivory on arthropods and leaf damage in some Guatamalan coffee plantations. Ecology 81:1750-1755.

Greenberg, R., P. Bichier, and J. Sterling. 1997. Bird populations in rustic and planted shade coffee plantations of eastern Chiapas, Mexico. Biotropica 29:501-514.

Greenberg, R., and J. S. Ortiz. 1994. Interspecific defense of pasture trees by wintering Yellow Warblers. Auk 111:672682.

Gruner, D. S. 2004. Attenuation of top-down and bottom-up forces in a complex terrestrial community. Ecology 85:30103022.

Halaj, J., and D. H. Wise. 2001. Terrestrial trophic cascades: how much do they trickle? American Naturalist 157:262-281.

Hedges, L. V., J. Gurevitch, and P. S. Curtis. 1999. The metaanalysis of response ratios in experimental ecology. Ecology 80:1150-1156.

Hulot, F. D., G. Lacroix, F. O. Lescher-Moutoue, and M. Loreau. 2000. Functional diversity governs ecosystem response to nutrient enrichment. Nature 405:340-344.

Jedlicka, J. A., R. Greenberg, I. Perfecto, S. M. Philpott, and T. V. Dietsch. 2006. Seasonal shift in the foraging niche of a tropical avian resident: resource competition at work? Journal of Tropical Ecology 22:385-395.

Johnson, M. D., T. W. Sherry, A. M. Strong, and A. Medori. 2005. Migrants in Neotropical bird communities: an assessment of the breeding currency hypothesis. Journal of Animal Ecology 74:333-341.

Marquis, R. J., and C. Whelan. 1996. Plant morphology, and recruitment of the third trophic level: subtle and littlerecognized defenses? Oikos 75:330-334.

Matta, F. M., R. A. Loos, R. Rodriguez, and R. S. Barros. 2001. Actual and potential photosynthetic rates of tropical crop species. Revista Brasileira Fisiologia Vegetal 13:24-32.

Moguel, P., and V. M. Toledo. 1999. Biodiversity conservation in traditional coffee systems of Mexico. Conservation Biology 13:11-21.

Mols, C., and M. Visser. 2002. Great tits can reduce caterpillar damage in apple orchards. Journal of Applied Ecology 39: 888-899.
Mooney, K. A., and Y. B. Linhart. 2006. Contrasting cascades: insectivorous birds increase pine but not parasitic mistletoe growth. Journal of Animal Ecology 75:350-357.

Oksanen, L., S. Fretwell, J. Arruda, and P. Niemela. 1981. Exploitation ecosystems in gradients of primary productivity. American Naturalist 118:240-261.

Pennington, T. D. 1997. The genus Inga. Continental Printing, Brussels, Belgium.

Perfecto, I., I. Ambrecht, S. M. Philpott, L. Soto-Pinto, and T. V. Dietsch. 2007. Shaded coffee and the stability of rainforest margins in Latin America. Pages 227-264 in T. Tscharntke, C. Leuschner, M. Zeller, E. Guhadja, and A. Bidin, editors. The stability of tropical rainforest margins, linking ecological, economic, and social constraints of land use and conservation. Springer, New York, New York, USA.

Perfecto, I., R. A. Rice, R. Greenberg, and M. E. Van der Voort. 1996. Shade coffee: a disappearing refuge for biodiversity. BioScience 46:598-608.

Perfecto, I., J. H. Vandermeer, G. L. Bautista, G. IbarraNuñez, R. Greenberg, P. Bichier, and S. Langridge. 2004. Greater predation in shaded coffee farms: the role of resident neotropical birds. Ecology 85:2677-2681.

Philpott, S. M., R. Greenberg, P. Bichier, and I. Perfecto. 2004. Impacts of major predators on tropical agroforest arthropods: comparisons within and across taxa. Oecologia 140: 140-149.

Polis, G. A., and D. R. Strong. 1996. Food web complexity and community dynamics. American Naturalist 147:813-846.

Rice, R. A., and R. Greenberg. 2000. Cacao cultivation and the conservation of biological diversity. Ambio 29:167-173.

Schmitz, O. J. 2007. Predator diversity and trophic interactions. Ecology 88:2415-2426.

Schmitz, O. J., P. A. Hamback, and A. P. Beckerman. 2000. Trophic cascades in terrestrial systems: A review of the effects of carnivore removals on plants. American Naturalist 155: $141-153$.

Shurin, J. B., E. T. Borer, E. W. Seabloom, K. Anderson, C. A. Blanchette, B. Broitman, S. D. Cooper, and B. S. Halpern. 2002. A cross-ecosystem comparison of the strength of trophic cascades. Ecology Letters 5:785-791.

Sih, A., G. Englund, and D. Wooster. 1998. Emergent impacts of multiple predators on prey. Trends in Ecology and Evolution 13:350-355.

Strong, D. R., J. H. Lawton, and R. Southwood. 1984. Insects on plants: community patterns and mechanisms. Harvard University Press, Cambridge, Massachusetts, USA.

Van Bael, S. A., P. Bichier, I. Ochoa, and R. Greenberg. 2007. Bird diversity in cacao farms and forest fragments of western Panama. Biodiversity and Conservation 16:2245-2256.

Van Bael, S. A., and J. D. Brawn. 2005. The direct and indirect effects of insectivory by birds in two contrasting Neotropical forests. Oecologia 143:106-116.

Wunderle, J. M., and S. C. Latta. 1996. Avian abundance in sun and shade coffee plantations and remnant pine forest in the Cordillera Central, Dominican Republic. Ornithologia Neotropical 7:19-34.

\section{APPENDIX A}

Supplementary methods for literature search, study selection, effect size calculations, and analyses of bird predation and diversity effects (Ecological Archives E089-053-A1).

\section{APPENDIX B}

A table describing bird exclosure studies included in meta-analysis (Ecological Archives E089-053-A2). 